\title{
Determinants of Felt Stigma among Patients Living with Epilepsy Attending a Tertiary Neurology Clinic in South East Nigeria
}

\author{
0. O. Onodugo', B. A. Ezeala-Adikaibe ${ }^{1,2^{*}}$, U. C. Ijoma ${ }^{1}$, J. U. Achor ${ }^{3}$, C. L. Onyekonwu1, \\ N. C. Mbadiwe1,2, C. C. Orjioke², E. I. Aneke², N. P. Ezeala-Adikaibe ${ }^{4}$ \\ ${ }^{1}$ Department of Medicine, University of Nigeria Teaching Hospital, Enugu, Nigeria \\ ${ }^{2}$ Department of Medicine, Enugu State University Teaching Hospital, Enugu, Nigeria \\ ${ }^{3}$ Federal Neuropsychiatric Hospital, Enugu, Nigeria \\ ${ }^{4}$ Department of Community Medicine, University of Nigeria Teaching Hospital Enugu, Nigeria \\ Email: ^birinusadikaibe@gmail.com
}

How to cite this paper: Onodugo, O.O., Ezeala-Adikaibe, B.A., Ijoma, U.C., Achor, J.U., Onyekonwu, C.L., Mbadiwe, N.C., Orjioke, C.C., Aneke, E.I. and Ezeala-Adikaibe, N.P. (2018) Determinants of Felt Stigma among Patients Living with Epilepsy Attending a Tertiary Neurology Clinic in South East Nigeria. Open Journal of Psychiatry, 8, 377-389.

https://doi.org/10.4236/ojpsych.2018.84029

Received: August 23, 2018

Accepted: October 19, 2018

Published: October 22, 2018

Copyright ( $\odot 2018$ by authors and Scientific Research Publishing Inc. This work is licensed under the Creative Commons Attribution International License (CC BY 4.0).

http://creativecommons.org/licenses/by/4.0/

(c) (i) Open Access

\begin{abstract}
Background: Felt stigma is a major social and psychological problem in epilepsy and manifests the fear or expectations of such "reactions" from people. Understanding of the pattern and prevalence of felt stigma gives an insight into the burden of this "second illness" of epilepsy in southeast Nigeria. Methods: Consecutive consenting adult epilepsy patients attending a neurology outpatient in Enugu southeast Nigeria were interviewed. Data on felt stigma was also collected using a scale for collection of stigma data on stigma designed by Jacoby et al. Results: A total of 295 patients were interviewed during the study (165 (55.9\%) males and 130 (44.1\%) females). About 29.4\% (88/295) felt stigmatized and $82.1 \%$ of them highly so. Correlates of felt stigma were age of onset (negatively), seizure frequency, duration of epilepsy, use of non-orthodox treatment, seizures occurring in public and the presence of physical injuries. Predictors of felt stigma were having seizures in public $(\mathrm{R} 2=0.232, \mathrm{p}<0.001)$ and seizure related injuries $(\mathrm{R} 2=0.277, \mathrm{p}<0.001)$. Conclusions: Felt epilepsy stigma is common among patients attending urban tertiary hospital in southeast Nigeria. Several preventable factors are associated with this phenomenon hence efforts aimed at preventing epilepsy should also target felt stigma prevention.
\end{abstract}

\section{Keywords}

Epilepsy, Felt Stigma, Seizures in Public, Seizure Related Injury

\section{Introduction}

Stigma remains a major social and psychological problem in epilepsy. It refers to 
the extent to which people with epilepsy are separated from society on the basis of the meanings that are attached to the term "epilepsy" [1]. These meanings and definitions vary widely between and within cultures and form the basis for "epilepsy reactions" among the populace [2]. Enacted stigma manifests as actual unacceptable "reaction" against people living with epilepsy (PLWE) because of epilepsy by others, whereas felt stigma is the fear or expectations of such "reactions" from people. Felt stigma is due to internalized feeling of shame, probably based on previous experiences or personal beliefs and therefore it is the fear and expectation of stigma from others [3].

The pattern, intensity and prevalence of both enacted and felt stigma depend on socio-cultural, economic, religious as well as several seizure-related and patient dependent variables [4] [5] [6] [7]. Therefore, the pattern and prevalence of felt stigma may vary with cultural perspectives and region/socioeconomic context where each person lives [7] [8]. Felt stigma is a barrier to recovery and has been linked to a broad range of psychosocial consequences. It has the potential to influence the provision of care to people with epilepsy [9] [10] [11] and has been described as "second illness" [12]. Felt stigma at the start of treatment may influence subsequent treatment behavior and is a predictor of treatment discontinuation [10] [11], may cause anxiety and reduce performance at work thus reinforcing preexisting prejudice [13].

The prevalence and pattern of felt stigma vary widely depending on the region studied and instrument used. Reports from sub Saharan Africa (SSA) range from $31.2 \%$ to $81 \%$ [5] [6] [14] [15] [16] [17] [18]. Similarly, wide variations have been reported from other regions. For instance, in other developing countries, it ranged from 33\% - 65.8\% [8] [18]. A report from 15 European countries [19] found a prevalence of $51 \%$. In Croatia, 53\% of PLWE reported feeling stigmatized [20] while in the US, $34 \%$ and $69 \%$ of PLWE on anti-epileptic drugs (AEDs) indicated some form of felt stigma [21]. Understanding of the pattern and prevalence of felt stigma gives an insight into the burden of this "second" [12] illness of epilepsy in SSA.

Aims: The major aim of this study was to evaluate the determinants and predictors of felt stigma among PLWE attending a tertiary facility in southeast Nigeria.

\section{Methodology}

\subsection{Design}

This was a cross-sectional descriptive study conducted among individuals receiving treatment for epilepsy in a tertiary referral specialist hospital. The study was carried out at the outpatient neurology service of the University of Nigeria Teaching Hospital, Ituku Ozalla Enugu. All consecutive consenting patients age 18 and above attending the medical neurology clinic of the University of Nigeria Teaching Hospital and Enugu State University Teaching Hospital were included in the study. Exclusion criteria were 1) refusal to participate, 2) chronic stigmatizing conditions such as HIV/AIDs and psychiatric disorders, 3) history 
of pseudo-seizures and 4) inability to speak simple English.

Participants who met the outlined inclusion criteria were interviewed with a semi-structured questionnaire, specifically designed by the investigators after a review of the relevant literature. Subjects were interviewed in the clinic. The questionnaire sought to elicit data on socio-demographic variables (sex, age, marital status and education), Seizure related variables (seizure frequency, age of onset, family history of epilepsy, use of non-orthodox treatment (NOT), history of seizure-related injury, having seizures in public). Data on felt stigma was also collected using a scale for assessing felt stigma designed by Jacoby et al. [22]. A clinic-based validation of a subset of a random sample of 30 individuals with epilepsy was done by a neurologist (BAE). The questionnaire exhibited an overall $100 \%$ sensitivity and specificity and was administered in English. Answers to interview questions were recorded on paper copies of the instrument along with study identification numbers. Names were not recorded on the instrument, but folder numbers were recorded. The scoring for felt stigma was dichotomous, with individuals answering "yes" or "no" to each of the component items. Interviews were conducted by the authors each lasting between 5 and 10 min (Please see attached questionnaire for the stigma-related questions asked). The reliability index using the Kuder Richardson-20 test was 0.98 .

Sample size was determined using standard tables for populations up to 1000 (based on the number of epilepsy patients attending our clinic), $\mathrm{p}$ was assumed to be 0.5 and a normal deviate of $5 \%$ level of significance (2-sided test) $=1.96$ [23].

Ethical clearance was obtained from the Hospital Ethical Committee.

Definition of terms.

NOT of epilepsy was defined as the use of herbal medicine, prayers and other forms of rituals as the sole treatment of epilepsy in the past.

\subsection{Data Analysis}

Data were analyzed using SPSS version 22, after due data cleaning. The raw scores were assembled, tallied, put in frequency table and analyzed. The scoring for each item was either "yes" or "no". Each "YESs" answer was scored as "1" and "NO" as " 0 ". The answers were summed up and their respective weights are as follows: No stigma $=0$, mild stigma $=1$, moderate stigma $=2$ and severe stigma $=3$. The relationships between variables were explored using the Chi squared test for comparison of proportions, and the students' T-test for comparing the differences in mean age of the participants. Correlation between felt stigma and other variables was calculated using Spearman's rho statistic. The level of statistical significance for all analyses was set at $\mathrm{p}<0.05$.

\section{Results}

\subsection{Characteristics of the Sample}

A total of 295 PLWE were interviewed during the study. One hundred and six- 
ty-five $(55.9 \%)$ were males and $130(44.1 \%)$ were females. Most of the patients were less than 35 years $(67 \%$ (200/295)). Males were significantly older (mean age $35.6( \pm 16.4)$ than females (mean age $30.9( \pm 13.8), p=0.01$. Although the peak age-of-onset of epilepsy was $11-20$ years in both males and females, epilepsy started earlier in females $(16.6 \pm 14.7$ years) than males $(22.9 \pm 20), \mathrm{P}<$ 0.01. Educational status and other variables are shown in Table 1 and Table 2. About $15.3 \%$ (45/295) reported a family history of epilepsy, $43.4 \%(128 / 295)$ used NOT in the past and $48.8 \%(144 / 295)$ and $44.7 \%$ (132/295) had experienced seizures in the public and sustained physical seizure related injuries respectively.

\subsection{Stigma}

About 29.4\% (88/295) of PLWE in the index study had experienced felt stigma at least once. The distribution of positive answers to the three categories of felt stigma is shown in Table 3. There was no significant difference in the gender distribution of stigma experiences. The most common form of felt stigma reported was feeling uncomfortable $28.5 \%$ (84/295). Levels of stigma are shown in Table 4 . About $81.2 \%$ (72/88) of those interviewed felt highly stigmatized. Severity

Table 1. Gender distribution of patient characteristics.

\begin{tabular}{|c|c|c|c|c|}
\hline & Male n (\%) & Female & Total & p-value \\
\hline Age (years) & - & - & - & \\
\hline$<25$ & $47(28.5)$ & $50(38.5)$ & $97(32.9)$ & \\
\hline $25-34$ & $53(32.1)$ & $50(38.5)$ & $103(34.9)$ & \\
\hline $35-44$ & $22(13.3)$ & $12(9.2)$ & $34(11.5)$ & \\
\hline$\geq 45$ & $43(26.1)$ & $18(13.8)$ & $61(20.7)$ & 0.03 \\
\hline Age of onset (years) & - & - & - & \\
\hline $0-10$ & $45(27.3)$ & $47(36.2)$ & $92(31.2)$ & \\
\hline $11-20$ & $56(33.9)$ & $46(35.4)$ & $102(34.6)$ & \\
\hline $21-30$ & $20(12.1)$ & $25(19.2)$ & $45(15.3)$ & \\
\hline$>30$ & $44(26.7)$ & $12(9.2)$ & $56(19)$ & 0.01 \\
\hline Time of last seizure & - & - & - & \\
\hline$<24$ hours & $28(17)$ & $28(21.5)$ & $56(19)$ & \\
\hline 1 week & $29(17.6)$ & $17(13.1)$ & $46(15.6)$ & \\
\hline 1 week- $<1$ month & $18(10.9)$ & $18(13.8)$ & $36(12.2)$ & \\
\hline $1-6$ months & $13(7.9)$ & $12(9.2)$ & $25(8.5)$ & \\
\hline$>6$ months- 1 year & $4(2.4)$ & $3(2.3)$ & $7(2.3)$ & \\
\hline$>1$ year to 3 years & $4(2.4)$ & $5(3.8)$ & $9(3.1)$ & \\
\hline$>3$ years & $69(41.8)$ & $47(36.2)$ & $116(39.3)$ & \\
\hline Educational status & - & - & - & - \\
\hline None & $18(10.9)$ & $8(6.2)$ & $26(8.8)$ & \\
\hline Primary & $35(21.2)$ & $14(10.8)$ & $49(16.6)$ & \\
\hline Secondary & $78(47.3)$ & $82(51.2)$ & $160(54.20$ & \\
\hline Tertiary & $34(20.6)$ & $26(20)$ & $60(20.3)$ & 0.02 \\
\hline Employment status & - & - & - & \\
\hline Employed & $84(50.9)$ & $54(41.5)$ & $157(46.8)$ & \\
\hline Not employed & $32(19.4)$ & $42(32.3)$ & $74(25.1)$ & \\
\hline Students & $49(29.7)$ & $34(26.2)$ & $21(28.1)$ & - \\
\hline Total & $165(55.9)$ & $130(44.1)$ & $295(100)$ & 0.04 \\
\hline
\end{tabular}


Table 2. Mean age of the patients and Seizure characteristics.

\begin{tabular}{|c|c|c|c|c|}
\hline & Male n (\%) & Female n (\%) & Total n (\%) & $\begin{array}{c}\mathrm{p} \text {-value for } \\
\text { mean }\end{array}$ \\
\hline Age (years) & - & - & - & \multirow{3}{*}{$\begin{array}{c}- \\
0.01\end{array}$} \\
\hline mean $(\mathrm{sd})$ & $35.6(16.4)$ & $30.9(13.8)$ & $33.5(15.5)$ & \\
\hline Median (range) & $30(17-88)$ & $27(16-88)$ & $29(16-88)$ & \\
\hline Age of onset (years) & - & - & - & \multirow{3}{*}{$\begin{array}{c}- \\
0.003\end{array}$} \\
\hline mean $(\mathrm{sd})$ & $22.9(20)$ & $16.6(14.7)$ & $20.1(18.1)$ & \\
\hline Median (range) & $17(0-81)$ & $15(0-80)$ & $16(0-81)$ & \\
\hline Duration of seizures & - & - & - & \multirow{3}{*}{-} \\
\hline mean $(\mathrm{sd})$ & $12.8(11.7)$ & $14.3(11.9)$ & $13.5(11.8)$ & \\
\hline Median (range) & $9(0-64)$ & $12(0-58)$ & $10(0-64)$ & \\
\hline Family history of epilepsy & - & - & - & - \\
\hline Yes & $30(18.2)$ & $15(11.5)$ & $45(15.3)$ & 0.12 \\
\hline Ability to predict seizures & - & - & - & - \\
\hline Yes & $89(53.9)$ & $74(56.9)$ & $163(55.3)$ & 0.61 \\
\hline I used non-orthodox treatment in the & - & - & - & - \\
\hline past. & $74(44.8)$ & $54(41.5)$ & $128(43.4)$ & 0.57 \\
\hline I have had seizures in the public & - & - & - & - \\
\hline Yes & $73(44.2)$ & $71(54.6)$ & $144(48.8)$ & 0.08 \\
\hline History of seizure related severe Injuries & - & - & - & - \\
\hline Yes & $71(43)$ & $61(46.9)$ & $132(44.7)$ & 0.5 \\
\hline
\end{tabular}

Table 3. Distribution of felt stigma questions*.

\begin{tabular}{ccccc}
\hline & Male & Female & Total & p-value \\
\hline $\begin{array}{c}\text { a) Some people are } \\
\text { uncomfortable with you }\end{array}$ & $40(24.2)$ & $44(33.8)$ & $84(28.5)$ & 0.07 \\
$\begin{array}{c}\text { b) Some people look down on you and } \\
\text { treat you like an inferior person }\end{array}$ & $41(24.8 \%)$ & $37(28.5 \%)$ & $78(26.4)$ & 0.05 \\
$\begin{array}{c}\text { c) Some people avoid you } \\
\text { Total number with felt stigma }\end{array}$ & $42(25.5)$ & $36(27.7)$ & $78(26.4)$ & 0.67 \\
\hline
\end{tabular}

* derived from Jacoby, A et $a l^{26}$.

Table 4. Severity of felt stigma.

\begin{tabular}{cccc}
\hline Level of stigma (0 none, 1 mild, 2 Moderate, 3 severe). & Male & Female & Total \\
\hline No perceived stigma & $122(73.9)$ & $85(65.4)$ & $207(70.2)$ \\
Mild & $2(1.2)$ & $6(4.6)$ & $8(2.7)$ \\
Moderate & $2(1.2)$ & $6(4.6)$ & $8(2.7)$ \\
Severe & $39(23.6)$ & $33(25.4)$ & $72(24.4)$ \\
\hline
\end{tabular}

of stigma in males and females were $73.3 \%(33 / 45)$ and $90.7 \%(39 / 43)$ respectively.

Several variables correlated with felt stigma depending on the age of the patients, Table 5. Overall, age of onset (negatively), seizure frequency, duration of epilepsy, use of NOT, seizures occurring in public and the presence of physical 
Table 5. Correlation of stigma within different age groups.

\begin{tabular}{|c|c|c|c|c|c|}
\hline \multicolumn{6}{|c|}{ Current Age } \\
\hline & $16-24(\mathrm{n}=97)$ & $25-34(n=103$ & $35-44(n=34)$ & $\geq 45(n=61)$ & $6-88(n=295)$ \\
\hline Age & $0.01(0.92)$ & $0.01(0.94)$ & $-0.05(0.76)$ & $-0.13(0.32)$ & $-0.11(0.07)$ \\
\hline Gender & $0.15(0.14)$ & $0.08(0.4)$ & $0.03(0.89)$ & $-0.9(0.49)$ & $0.08(0.2)$ \\
\hline Level of education & $-0.32(0.002)$ & $-0.24(0.02)$ & $0.1(0.57)$ & $0.15(0.25)$ & $-0.08(0.17)$ \\
\hline $\begin{array}{l}\text { Occupational status } \\
\quad(1 \text { yes, } 0 \mathrm{No})\end{array}$ & $0.02(0.83)$ & $-0.03(0.79)$ & $-0.08(0.66)$ & $0.38(0.002)$ & $0.047(0.42)$ \\
\hline Age of onset & $-0.13(0.2)$ & $-0.13(0.2)$ & $-0.23(0.2)$ & $-0.02(0.87)$ & $-0.17(0.005)$ \\
\hline $\begin{array}{l}\text { Affected siblings } \\
\quad(1 \text { yes, } 0 \text { no })\end{array}$ & $-0.08(0.44)$ & $-0.13(0.2)$ & $0.44(0.01)$ & $0.17(0.17)$ & $0.1(0.1)$ \\
\hline Seizure frequency & $0.08(0.44)$ & $0.17(0.09)$ & $0.32(0.06)$ & $0.16(0.21)$ & $0.14(0.01)$ \\
\hline Duration of epilepsy & $0.14(0.16)$ & $0.16(0.11)$ & $0.27(0.12)$ & $-0.06(0.62)$ & $0.11(0.01)$ \\
\hline Seizure predictability & $0.09(0.39)$ & $0.13(0.2)$ & $0.2(0.26)$ & $-0.04(0.76)$ & $0.11(0.07)$ \\
\hline Use of NOT & $0.1(0.35)$ & $0.34(<0.001)$ & $0.2(0.27)$ & $-0.14(0.28)$ & $0.17(0.003)$ \\
\hline $\begin{array}{l}\text { Seizure occurring } \\
\text { outside home }\end{array}$ & $0.56(<0.001)$ & $0.48(<0.001)$ & $0.34(0.001)$ & $0.37(0.004)$ & $0.38(<0.001)$ \\
\hline Injury & $0.33(0.001)$ & $0.38(<0.001)$ & $0.74(<0.001)$ & $0.05(0.73)$ & $0.38(<0.001)$ \\
\hline Variable seizure types & $0.08(0.433)$ & $-0.19(0.05)$ & $-0.1(0.57)$ & $0.06(0.63)$ & $-0.05(0.39)$ \\
\hline
\end{tabular}

injuries correlated with felt stigma. Having seizures in public correlated with felt stigma irrespective of age. Before the age of 45 , seizure related injury was a significant correlate of felt stigma. In patients older than 44 years, having a job correlated with felt stigma. Predictors of felt stigma were having seizures in public $(\mathrm{R} 2=0.23, \mathrm{p}<0.001)$ and seizure related injuries $(\mathrm{R} 2=0.28, \mathrm{p}<0.001)$, Table 6 .

\section{Discussion}

In SSA, PLWE experiences stigma in several areas of life [5] [6] [14] [15] [16] [17] [24]. Over time these experiences may become internalized resulting in an expectation of stigma. This expectation of stigma (felt stigma) may lead to depression, anxiety, non-disclosure, concealment of epilepsy, treatment gap and other life disruptions [9] [10] [11] [12]. This study suggests that felt stigma is a major concern in about a third of PLWE attending a tertiary medical center in Enugu southeast Nigeria. About 29.4\% experienced felt stigma and most (81.8\%) severely so. Although felt stigma was similar in males and females, several correlates were found depending on the age of the patients. Seizures occurring in public positively correlated with felt stigma independent of the age of the patient. Patients who were aged $\geq 45$ years and having a job positively correlated with felt stigma. Factors that positively predicted the presence of felt stigma were having seizure in public and seizure related injuries.

Patient and seizures related characteristics in this study are similar to previous studies from the same region [16] [25]. Family history of epilepsy was observed 
Table 6. Predictors of felt stigma.

\begin{tabular}{cccc}
\hline Variable & $\mathrm{R}^{2}$ & Beta (SE) & p-value \\
\hline Age of onset & - & $-0.005(0.004)$ & 0.233 \\
Seizure frequency & - & $0.123(0.177)$ & 0.489 \\
Duration of epilepsy & - & $0.002(0.007)$ & 0.812 \\
Use of non-orthodox medicine & - & $-0.061(0.142)$ & 0.668 \\
Having seizure in public & 0.232 & $1.002(0.144)$ & $<0.001$ \\
Seizure related injuries & 0.277 & $0.583(0.147)$ & $<0.001$ \\
\hline
\end{tabular}

in about $15.3 \%$ of the patients which is lower than $25 \%$ - 60\% reported by Preux and Druet-Cabanac [26]. Widespread risks factors for epilepsy in many African communities may affect several members of the same family. Seizure control over the preceding three years were $39.3 \%$ and $44.7 \%$ within one year. One reason for such a low rate of seizure control may be the inclusion of drug naïve patients and new onset epilepsy. Furthermore, our cohort was selected from those attending a tertiary hospital neurology clinic severe forms of epilepsy may be referred.

Most PLWE who felt stigmatized (29.4\%) were highly stigmatized (81.8\%). Highly stigmatized females and males were $73.3 \%$ (33/45) and 90.7\% (39/43) respectively. Reports on gender differences in epilepsy related felt stigma has been conflicting [5] [6] [14] [15] [16] [17] [24]. The high proportion of highly stigmatized male patients may be attributed to several factors. Firstly, males are more likely to socialize than females, hence may be exposed to enacted felt stigma. Secondly, stigma at the work place is more likely to be experienced by men who were also more likely to be employed (50.9\% v $41.5 \%)$. Finally, social role expectations suggest that males were more likely to engage in several activities to meet their family needs. Studies have shown that the prevalence of felt stigma in epilepsy vary both between and within countries. In Ethiopia a prevalence of 31.2\% and $81 \% 5$ [5] [15] was reported. In Kenya [14], a prevalence rate of 33\%was reported and in Benin Republic 68.7\% was reported [17]. Achor et al. [16] reported a prevalence of $46.2 \%$ in Enugu using the same instrument. Outside the continent, prevalence of felt stigma has been reported. In the middle east, a prevalence of $33 \%$ was reported [8] while in Europe and the Americas the estimated prevalence of felt stigma were $51 \%$ and $46 \%$, and $69 \%$ [19] [20] [21] respectively. These wide differences might be due to study settings, socio-cultural differences, the population studied as well as the instrument used.

In the index study, age-of-onset negatively correlated with felt stigma while seizure frequency, duration of epilepsy, use of NOT, having seizures in public and seizure related injuries positively correlated with felt stigma. Occupational status correlated with felt stigma in PLWE aged 45 years and above. Unlike previous studies, we did not find a significant correlate between felt stigma and current age of the patients [5] [15]. Some of these findings were similar to pre- 
vious studies [4] [14] [15]. One major contributor to the relationship between felt stigma and having a job may be enacted stigma in the work place. Felt stigma makes patients more anxious and actually perform worse at work thus reinforcing the prejudice they encounter [13]. The relationship between felt stigma and earlier age of onset may be attributed to the fact that epilepsy beginning at an early age may increase the chances of exposure to circumstances that promote discrimination and feelings of shame. This is particularly significant considering the level of awareness and practice of epilepsy in school and the community. Earlier studies had documented the perception of families about epilepsy and the effect of early age of onset of epilepsy in fostering stigmatization as well as contributing to the poor social outcomes associated with epilepsy [15] [27] [28] [29]. It has been hypothesized that early onset epilepsy may lead to felt stigma through the phenomenon of stigma "coaching" which is as a result of the attitudes and behaviors of older individuals [29]. These same reasons may also apply to the positive correlation between felt stigma and duration of epilepsy. The relation between seizure frequency, having seizures in public and seizure related injuries and felt stigma has been previously documented [4] [5] [6] [14] [15] [19]. Seizure frequency has also been related to seizure related injuries, absenteeism, unemployment and poor quality of life [29] [30]. Results from the index study may be a reflection of poor seizure control among the cohort studied. The contribution of epilepsy-related injuries like burns in promoting stigma in Africa has been documented [24].

The use of NOT also correlated with felt stigma. The relationship between felt stigma and NOT practices may not be direct. Although these patients used NOT prior to the index study, using these forms of treatment increases the risk of having seizures in public, seizure related injuries, forced disclosure and status epilepticus. The contribution of seizure related injuries to epilepsy related stigma becomes more burdensome if NOT-treatment related scarification marks are taking into consideration in SSA.

Having seizures in public spaces which is equivalent to forced disclosure and seizure related injuries were the only significant predictors of felt stigma. This indicates that measures aimed at reducing these two variables would go a long way in reducing the burden of felt stigma. These include medication adherence, access to care as well as lifestyle modifications/avoidance of certain activities like climbing heights. This underscores the need to promote epilepsy care, counseling and treatment at the primary healthcare levels especially in rural and isolated communities in Nigeria. Efforts should be made to give epilepsy more emphasis in the curriculum of medical/nursing schools as well as those of allied professions. There is also the need to provide correct information about epilepsy through sources that are credible to target the larger community, PLWE and their families.

The impact of epilepsy-related felt stigma on both disease burden and quality of life cannot be over emphasized in SSA where epilepsy rates remain very high. 
Working towards improved treatment accessibility for PLWE should be coupled with efforts directed toward public education about the condition.

Some of the limitations of this study are worthy of note. Our cohort was selected from a pool of PLWE attending tertiary hospital. This may lead to over recruitment of people with severe forms of epilepsy. Although the assessment of felt stigma was done with a three-item instrument which has been validated in Zambia, the use of more complex ethnographically derived instruments might yield different results. Seizure frequency and some other variables might have been affected by recall bias. Nevertheless, this study has provided reference data for future studies in Nigeria and other parts of SSA.

\section{Conclusion}

The burden of felt epilepsy stigma is high among patients attending urban tertiary hospital in southeast Nigeria. Several preventable factors are associated with this phenomenon. Efforts aimed at preventing epilepsy should also target stigma prevention.

\section{Acknowledgements}

The authors would like to acknowledge Miss Loveth Emmanuel, Secretary, Neurology and EEG services, Mount Carmel Hospital Enugu, for her help in the office.

\section{Disclosure}

The authors have nothing to disclose.

\section{Funding}

The present work did not receive any external funding.

\section{Statement of Authorship}

BAEA, AUJ conceived the study; BAEA, AUJ designed the study protocol; BAEA, CCO, EIA, CLO, NPEA carried out the survey and sorted out the final data; BAEA, AUJ, EIA, OON NCM UNI drafted the manuscript; BAEA, AUJ, CCO, EIA, CLO, NPEA OON NCM UNI critically revised the manuscript for intellectual content; all authors read and approved the final manuscript. BAEA, AUJ are guarantors of the paper.

\section{Conflicts of Interest}

The authors declare no conflicts of interest regarding the publication of this paper.

\section{References}

[1] Reis, R. and Mernardi, H. (2002) ILAE/WHO "Out of the Shadows Campaign" Stigma: Does the Flag Identify the Cargo? Epilepsy and Behaviour, 3, 33-37. https://doi.org/10.1016/S1525-5050(02)00546-2 
[2] Jacoby, A., Wang, W., Vu, T.D., Wu, J., Snape, D., Aydemir, N., Parr, R., Reis, R., Begley, C., de Boer, H., Prilipko, L. and Baker, G. (2008). Meanings of Epilepsy in Its Sociocultural Context and Implications for Stigma: Findings from Ethnographic Studies in Local Communities in China and Vietnam. Epilepsy and Behaviour, 12, 286-297. https://doi.org/10.1016/j.yebeh.2007.10.006

[3] Ritsher, J.B. and Phelan, J.C. (2004) Internalized Stigma Predicts Erosion of Morale among Psychiatric Outpatients. Psychiatry Research, 129, 257-265.

https://doi.org/10.1016/j.psychres.2004.08.003

[4] Shi, Y., Wang, S., Ying, J., Zhang, M., Liu. L. and Sun, J. (20017) Correlates of Perceived Stigma for People Living with Epilepsy: A Meta-Analysis. Epilepsy and Behaviour, 70, 198-203.

[5] Fanta, T., Azale, T., Assefa, D. and Getachew, M. (2015) Prevalence and Factors Associated with Perceived Stigma among Patients with Epilepsy in Ethiopia. Journal of Psychiatry, 18, 324-331.

[6] Mbuba, C.K., Abubakar, A., Odermatt, P., Newton, C.R. and Carter, J.A. (2012) Development and Validation of the Kilifi Stigma Scale for Epilepsy in Kenya. Epilepsy and Behaviour, 24, 81-85. https://doi.org/10.1016/j.yebeh.2012.02.019

[7] Fernandes, P.T., Salgado, P.C., Noronha, A.L., de Boer, H.M., Priliko, L., Sander, J.W. and Li, L.M. (2007) Epilepsy Stigma Perception in an Urban Area of a Limited-Resource Country. Epilepsy and Behaviour, 11, 25-32.

https://doi.org/10.1016/j.yebeh.2007.02.020

[8] Baker, G.A., Jacoby, A., Gorry, J., Doughty, J. and Elina, V. (2005) Quality of Life of People with Epilepsy in Iran, the Gulf, and Near East. Epilepsia, 46, 132-140.

https://doi.org/10.1111/j.0013-9580.2005.20704.x

[9] Link, B.G., Struening, E.L., Neese-Todd, S., Asmussen, S. and Phelan, J.C. (2001) Stigma as a Barrier to Recovery: The Consequences of Stigma for the Self-Esteem of People with Mental Illnesses. Psychiatry Services, 52, 1621-1627. https://doi.org/10.1176/appi.ps.52.12.1621

[10] Sirey, J.A., Bruces, M.L., Alexopoulos, G.S., Perlick, D.A., Raue, P., Friedman, S.J. and Meyers, B.S. (2001) Perceived Stigma as a Predictor of Treatment Discontinuation in Young and Older Outpatients with Depression. American Journal of Psychiatry, 158, 479-481. https://doi.org/10.1176/appi.ajp.158.3.479

[11] Sirey, J.A., Bruce, M.L., Alexopoulos, G.S., Perlick, D.A., Friedman, S.J. and Meyers, B.S. (2001) Stigma as a Barrier to Recovery: Perceived Stigma and Patient-Rated Severity of Illness as Predictors of Antidepressant Drug Adherence. Psychiatry Services, 52, 1615-1620. https://doi.org/10.1176/appi.ps.52.12.1615

[12] Corrigan, P. (2004) How Stigma Interferes with Mental Health Care. American Psychologist, 59, 614-625. https://doi.org/10.1037/0003-066X.59.7.614

[13] Henry, J.D., von Hippel, C. and Shapiro, L. (2010) Stereotype Threat Contributes to Social Difficulties in People with Schizophrenia. British Journal of Clinical Psychology, 49, 31-41. https://doi.org/10.1348/014466509X421963

[14] Atadzhanov, M., Haworth, A., Chomba, E.N., Mbewe, E.K. and Birbeck, G.L. (2010) Epilepsy-Associated Stigma in Zambia: What Factors Predict Greater Felt Stigma in a Highly Stigmatized Population? Epilepsy and Behaviour, 19, 414-418. https://doi.org/10.1016/j.yebeh.2010.08.017

[15] Shibre, T., Alem, A., Tekle-Haimanot, R. and Medhin, G. (2006) Perception of Stigma in People with Epilepsy and Their Relatives in Butajira, Ethiopia. Ethiopian Journal of Health Development, 20, 170-176. 
[16] Achor, J.U., Ezeala-Adikaibe, B.A., Obayi, O.N., Ezeruigbo, C.F.S., Ekenze, O.S. and Onodugo, O.D. (2017) The Stigma of Epilepsy among Outpatients in a Tertiary Hospital in South-East Nigeria. Open Journal of Psychiatry, 7, 344-364. https://doi.org/10.4236/ojpsych.2017.74029

[17] Rafael, F., Houinato, D., Nubukpo, P., Dubreuil, C.M., Tran, D.S., Odermatt, P., Clement, J.P., Weiss, M.G. and Preux, P.M. (2010) Sociocultural and Psychological Features of Perceived Stigma Reported by People with Epilepsy in Benin. Epilepsia, 51, 1061-1068. https://doi.org/10.1111/j.1528-1167.2009.02511.x

[18] Luna, J., Nizard, M., Becker, D., Cruz, A., Ratsimbazafy, V., Dumas, M., Cruz, M. and Preux, P.M. (2017) Epilepsy-Associated Levels of Perceived Stigma, Their Associations with Treatment, and Related Factors: A Cross-Sectional Study in Urban and Rural Areas in Ecuador. Epilepsy \& Behaviour, 6, 71-77.

https://doi.org/10.1016/j.yebeh.2016.12.026

[19] Baker, G., Brooks, J., Buck, D. and Jacoby, A. (1999) The Stigma of Epilepsy: A European Perspective. Epilepsia, 41, 98-104. https://doi.org/10.1111/j.1528-1157.2000.tb01512.x

[20] Bielen, I., Friedrich, L., Sruk, A., Prvan, M.P., Hajnsek, S., Petelin Z, Susak, R., Cabrlic, M. and Jacoby, A. (2014) Factors Associated with Perceived Stigma of Epilepsy in Croatia: A Study Using the Revised Epilepsy Stigma Scale. Seizure, 23, 117-121. https://doi.org/10.1016/j.seizure.2013.10.008

[21] Prus, N. and Grant, A.C. (2010) Patient Beliefs about Epilepsy and Brain Surgery in a Multi-Cultural Urban Population. Epilepsy and Behaviour, 17, 46.

[22] Jacoby, A., Baker, G., Smith, D., Dewey, M. and Chadwick, D. (1993) Measuring the Impact of Epilepsy: The Development of a Novel Scale. Epilepsy Research, 16, 83-88. https://doi.org/10.1016/0920-1211(93)90042-6

[23] Yamane, T. (1967) Statistics: An Introductory Analysis. 2nd Edition, Harper and Row, New York.

[24] Baskind, R. and Birbeck, G.L. (2005) Epilepsy-Associated Stigma in Sub-Saharan Africa: The Social Landscape of a Disease. Epilepsy \& Behavior, 7, 68-73.

https://doi.org/10.1016/j.yebeh.2005.04.009

[25] Onwuekwe, I.O., Onodugo, O.D., Ezeala-Adikaibe, B.A., Aguwa, E.N., Ejim, E.C., Ndukuba, K., Abadom, T.R., Ilo, C.K. and Onyeizu, C. (2009) Pattern and Presentation of Epilepsy in Nigerian Africans: A Study of Trends in the Southeast. Transactions of the Royal Society of Tropical Medicine and Hygiene, 103, 785-789. https://doi.org/10.1016/j.trstmh.2009.04.010

[26] Preux, P.M. and Druet-Cabanac, M. (2005) Epidemiology and Aetiology of Epilepsy in Sub-Saharan Africa. The Lancet Neurology, 4, 21-31. https://doi.org/10.1016/S1474-4422(04)00963-9

[27] Joseph, N., Ray, A., Reshma, BK., Bhat, S., Herady, M., Kumar, A. and Shri Kiran, K. (2011) Assessment of Quality of Life, Stigma Associated and Self-Management Practices among Patients Suffering from Epileptic Seizures: A Cross Sectional Study. Journal of Neuroscience and Behavioural Health, 3, 91-98.

[28] Scambler, G. (2011) Epilepsy, Stigma and Quality of Life. Neurology Asia, 16, 35-36.

[29] Elwes, R.D.C., Marshall, J., Beattie, A. and Newman, P.K. (1991) Epilepsy and Employment. A Community Based Survey in an Area of High Unemployment. Journal of Neurology, Neurosurgery and Psychiatiatry, 54, 200-203. https://doi.org/10.1136/jnnp.54.3.200

[30] Jacoby, A. and Baker, G. (2001) Quality of Life in Epilepsy: Beyond Seizure Counts in Assessment and Treatment. Harwood Academic Publishers, Amsterdam. 


\section{Felt Stigma Questionnaire}

This questionnaire is designed to find out if have felt stigmatized in the past because of epilepsy. By "felt stigma" we mean your personal opinion or feelings about what people were doing or saying as they relate to you.

Please feel free to ask for clarification if you want.

Every information given will be kept confidential. (Please check all that apply)

Date of assessment

Folder number

Demographic/Personal

Name: (initials) Age Gender M $\mathrm{F}$ Level of education

Occupation Working Not working Student

Marital status Married Single Widowed Separated

Phone Number: (or Phone number of next-of-kin)

Tribe Town

Referred from:

\section{Clinical characteristics}

At what age did you start having convulsions?

At what age did you first go to the Hospital?

\section{Family/Genetic History}

Are your parents from the same town $\mathrm{Y} \quad \mathrm{N}$

$\begin{array}{lll}\text { Are your parents distant relatives } & \mathrm{Y} & \mathrm{N}\end{array}$

Affected siblings? No If yes, how many:

Any other family members with seizures?

No If yes, please explain:

\section{Seizures}

1) How often can you predict a seizure (check one)? (Always) (Most of the time) (Rarely) (Never)

2) If you can predict your seizures, what changes or experiences do you have?

Describe

3) Are all the seizures alike? $\quad \mathrm{Y} \quad \mathrm{N}$

4) Date of Last Seizure (Approximate length of time in moths or weeks)

5) Have you had seizures outside your family setting e.g. at school, church or market?

Y N

6) Have you sustained ever sustained injuries while having seizures?

$\mathrm{Y} \quad \mathrm{N}$

7) Since the onset of seizures (epilepsy) have used traditional or locallherbal medicine?

$\mathrm{Y} \quad \mathrm{N}$

8) Since the onset of seizures (epilepsy) have used prayers, deliverance sessions and other spiritual remedies as sole means of treating seizures (epilepsy)? 
Y N

Stigma Scale by Jacoby et al.

Because of my sickness (epilepsy):

a) I feel that some people are uncomfortable with me. $\quad \mathrm{Y} \quad \mathrm{N}$

b) I feel some people treat me like an inferior person. $\quad \mathrm{Y} \quad \mathrm{N}$

c) I feel some people would prefer to avoid me. $\quad$ Y $\quad N$ 